\title{
FREEZING OF THE SUBBALLAST LAYERS OF THE RAILWAY FORMATION - HIGH EMBANKMENT AND DOUBLE TRACK
}

\author{
Stanislav HODÁS ${ }^{1,{ }^{*}}$, Alžbeta PULTZNEROVÁ ${ }^{1}$ \\ ${ }^{1}$ Department of Railway Engineering and Track Management, Faculty of Civil Engineering, University \\ of Žilina, Univerzitná 8215/1, 01026 Žilina, Slovakia. \\ corresponding author: stanislav.hodas@fstav.uniza.sk.
}

\section{Abstract}

In the paper, a numerical modelling experiment is presented in order to detect the temperature transition through the individual layers of the railway formation during the winter period that is their undesirable freezing. In the experiment, the temperature behaviour and the zero isotherm $\left(0^{\circ} \mathrm{C}\right)$ are investigated. We want to prove that the temperatures are also affected by the volume of mass in the railway formation. The modelling of new experiment has been carried out done on a low and also high embankment of single and double track railway, where the volume of material in the core of the formation is almost doubled. The experiment demonstrated that the greater is the mass of the subballast layers, the higher is the resistance to freezing due to the accumulated heat in the pre-winter period.
\end{abstract}

\section{Keywords:}

Railway engineering: Numerical modelling; SV-HEAT;

Foundation freezing;

Single-track and double-track.

\section{Introduction}

At the Department of Railway Engineering, the research work in the field of investigation of the effects of frost on the subgrade on models built "in-situ" as well as their own numerical modelling using software SV-HEAT [1] have been carried out. The results are mutually compared (measured and modelled). The models were built as a structural type of TYPE 1 and TYPE 2 of the foundation in a single-track embankment (low embankment).

The research extension is an experiment dedicated to numerical modelling and frost effect validation on models with high embankment - TYPE 2 profile of a single-track and double-track. The reason for the model experiment is the fact that the larger mass in the core of the railway formation is better resistant to the effects of frost. The larger core of the embankment keeps more heat in the rail formation. In the end of the evaluation, all the observed model situations will be shown for comparison in the figures and tables for the different snow load, i.e. different snow thicknesses.

In the research, the load models are selected for the total freezing index $I_{f}=-600{ }^{\circ} \mathrm{C}$, which represents an over average frosty winter period in the climatic conditions of the Slovak Republic (it can be stated that the temperature load corresponding to this winter from the town of Poprad, i.e. the High Tatras region, is used in models in our experiment).

\section{Characteristics of layers of models and load from the external environment}

The material of layer used for the numerical model experiment is identical with the material of our "in-situ" models at the Railway Engineering Department, by authors [2] in 2014 and in the world [3], [4] and [5]. The material and technical characteristics of these structural layers $R_{i}$, which are applied to the MODEL 4, are shown in Tab.1, where: $\lambda$ - thermal conductivity, $\rho$ - bulk density, $c$ - specific thermal capacity and $w$ - volume content of water. The characteristics were obtained directly in the accredited laboratory of the Railway Engineering Department in [6] and [7], in accordance with research activities of the VEGA [8] in 2016 to 2018 and some parts of [9] in 2017. 
The dimensional distribution of these layers of the rail formation for the height of the protective layer $h_{F P L}=450 \mathrm{~mm}$ and $h_{F P L}=600 \mathrm{~mm}$ is presented in Fig. 4 and Fig. 5 .

Table 1: Input data - material-technical characteristics of the experiment.

\begin{tabular}{|c|c|c|c|c|c|}
\hline \multirow{2}{*}{$\boldsymbol{R}_{\boldsymbol{i}}$} & \multirow{2}{*}{ Material } & $\boldsymbol{\lambda}$ & $\boldsymbol{\rho}$ & $\boldsymbol{c}$ & $\boldsymbol{w}$ \\
\cline { 3 - 6 } & & $\mathbf{J} /($ day.m.C) & $\mathbf{k g} / \mathbf{m}^{\mathbf{3}}$ & $\mathbf{J} /(\mathbf{k g} \cdot \mathbf{C})$ & $\%$ \\
\hline R1 & Railway bed (RB) & 58147 & 1908 & 980 & 1.3 \\
\hline R2 & Protected layer (FPL) & 145853 & 2045 & 1246 & 5.4 \\
\hline R3 & Embankment & 116166 & 2129 & 1216 & 5.5 \\
\hline R4 & Railway subgrade & 78710 & 1646 & 1495 & 18.0 \\
\hline R5-R8 & Topsoil & 120960 & 1800 & 1000 & 20.0 \\
\hline
\end{tabular}

The model was loaded during 120 days in the winter period from 10 November (year) to 10 March (year +1$)$. In the study, 5 model climatic loads were solved: MODEL $1\left(I_{f 120}=-252^{\circ} \mathrm{C}\right)$, MODEL $2\left(I_{f 120}=-150{ }^{\circ} \mathrm{C}\right)$, MODEL $3\left(I_{f 120}=-375^{\circ} \mathrm{C}\right)$, MODEL $4\left(I_{f 120}=-600^{\circ} \mathrm{C}\right)$ and finally extreme winter MODEL $5\left(I_{f 120}=-800^{\circ} \mathrm{C}\right)$, [10] in 2017. MODEL 1 and MODEL 2 are also built in the "in-situ" area of the KZSTH laboratory. MODEL 3 is a combination of MODEL 1 and MODEL 2 (selecting of bad winter conditions from both). Numerical MODEL 4 represents the winter climatic load in the Poprad area (High Tatras Mountain Range) and the numerical MODEL 5 is increased by $30 \%$ in the freezing effect of MODEL 4. The research was published in 2014 by authors [11], [2] and their climatic loads by the mean daily temperatures $T_{s}$ are shown in Fig. 1.

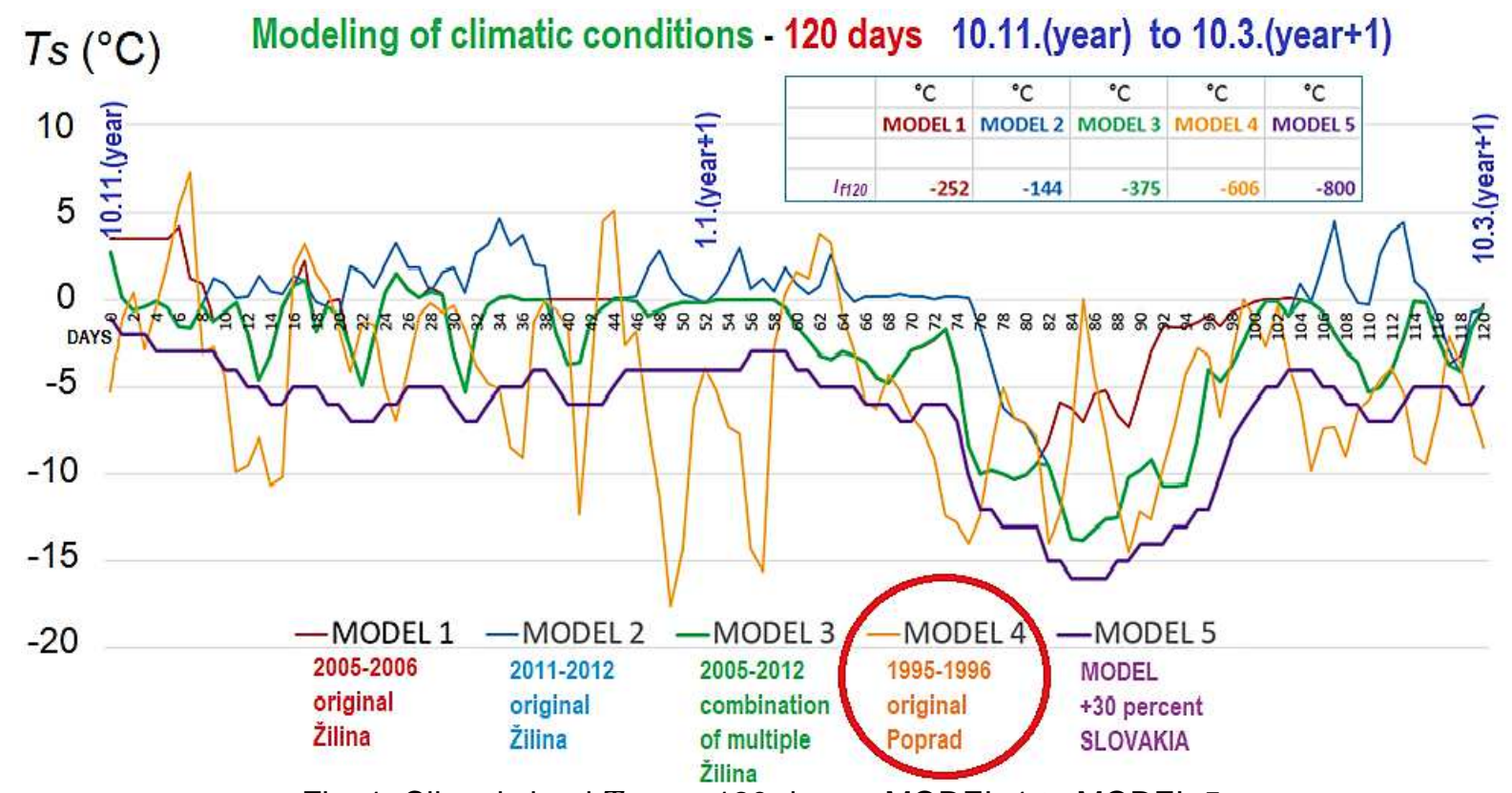

Fig. 1: Climatic load $T_{s}$ over 120 days - MODEL 1 to MODEL 5.

In the following text, we focus only on the MODEL $4\left(I_{f 120}=-600^{\circ} \mathrm{C}\right)$ where we will make the analysis (case of a strong winter in our location). We will investigate, by the numerical modelling, the depth of freezing, i.e. whether the zero isotherm $\left(0^{\circ} \mathrm{C}\right)$ endangers the subgrade layers of the $\mathrm{R} 3$ area (also using R2 - protective layer to eliminate frost effects and improve water proof characteristics), in figures Fig. 3 to Fig. 5.

\section{Preparation of the model experiment}

The main idea of the experiment is to compare the depth of freezing of subgrade of a railway formation with high embankment of the single-track and double-track railway. In the first case, it is 
assumed that the accumulated heat will be in the core of the railway formation with higher values than in the models examined until now in [2] and [6]. Subsequently, a double-track railway model will be realized in which the core of the double-track formation (R4) has larger width span (also with high embankment). In our experiment we will call our numerical model with climatic load the MODEL 4, which is characterized by the value of $I_{f 120}=-600{ }^{\circ} \mathrm{C}$ (MODEL 1 to 3 are published in journal [10]). We must verify how the volume corresponding to the R4 area affects the railway formation subgrade freezing, Fig. 3 to Fig. 5.

The experiment has been developed over a period of 120 days from the first frosts to the end of the winter (i.e. from November to March of the following year).

The verification will be done with a protective layer (FPL) with thickness $h_{F P L}=450 \mathrm{~mm}$ and 600 $\mathrm{mm}$ with different thickness of the snow layer $h_{\text {snow }}=0.00$ to $0.30 \mathrm{~m}$ (i.e. $0.00,0.10,0.20$ and $0.30 \mathrm{~m}$, which significantly affects the process of the freezing of the railway subgrade layers.

The passing train adjusts the height of the snow between rail tracks approx. the maximum value can be approx. $5 \mathrm{~cm}$ above the top surface of the rail head (bottom structure gauge). But outside the structure gauge area, the snow layer can be even higher, with the need to combine the desired individual sections of the transverse profile from experimental results at different thicknesses of the snow $h_{\text {snow }}$ (for example: rails, slope, shallow paved channel, etc.). Similar considerations as described in this text also apply to the railway track in cut, but this will be described in another experiment.

The snow cover on the railway structure greatly affects the behaviour of the zero isotherm (depth at $0^{\circ} \mathrm{C}$ ). In the case of hard frost (snow-free winter), unwanted freezing of the subgrade layers (Fig. 2a, Fig. 6a and Fig. 7a) will occur. Further graphs are for the snow cover from the initial snowfall, with the course of the winter, to the final reduction of the height of the snow layer at the end of the season. The course of the snowing graph phases is the same, but the difference is only in the height of the snow layer $h_{\text {snow }}$, Fig. 2.
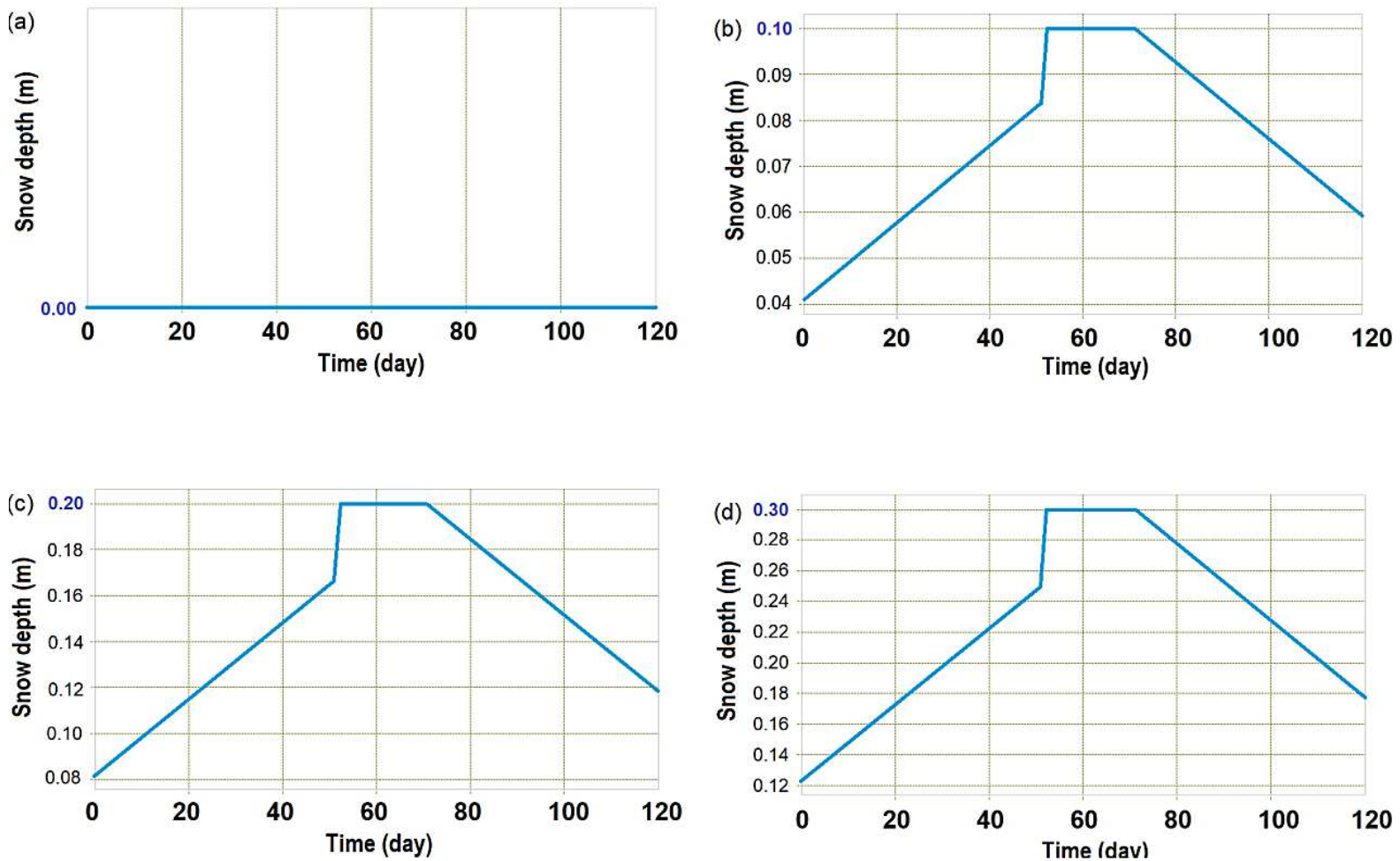

Fig. 2: The course of the depth of the snow layer $h_{\text {snow }}$ during the experiment.

\section{High embankment - model experiment}

The technical form of the cross section of the railway subgrade of TYPE 2 with the protective layer (FPL) was used for the model of the high embankment, Fig. 3 and Fig. 4. This numerical experiment can also be affected by the initial temperatures set in the individual layers $R_{i}$, which are accumulated during the summer and autumn periods (continuous cycle). It is assumed that higher temperatures are kept in these individual layers because the core of the formation has a larger volume 
(i.e. a larger cross-sectional area) and also applies to the material below the embankment rail formation.

The resulting effect of modelling of temperature regime without snow $h_{\text {snow }}=0.00 \mathrm{~m}$ is shown in Fig. 6a, where this structure (at $h_{F P L}=0.45 \mathrm{~m}$ ) does not suit from the temperature point of view. The freezing was $1.25 \mathrm{~m}$ deep in the center of the track. If we load the structure with snow $h_{\text {snow }}=0.10 \mathrm{~m}$ (snow is a good thermal insulator), the course is improved in the middle of the track, but under the rails the thickness of freezing exceeded the limit (Fig. 6b); we can say that these are partially frozen subgrade layers. The numerical model shows that at thickness $h_{\text {snow }}=0.20 \mathrm{~m}$ the structure keeps a zero isotherm at the desired depth (Fig. 6c, Fig. 7c, for $h_{\text {snow }}=0.30 \mathrm{~m}$ are Fig. $6 \mathrm{~d}$ and Fig. $7 \mathrm{~d}$ ).

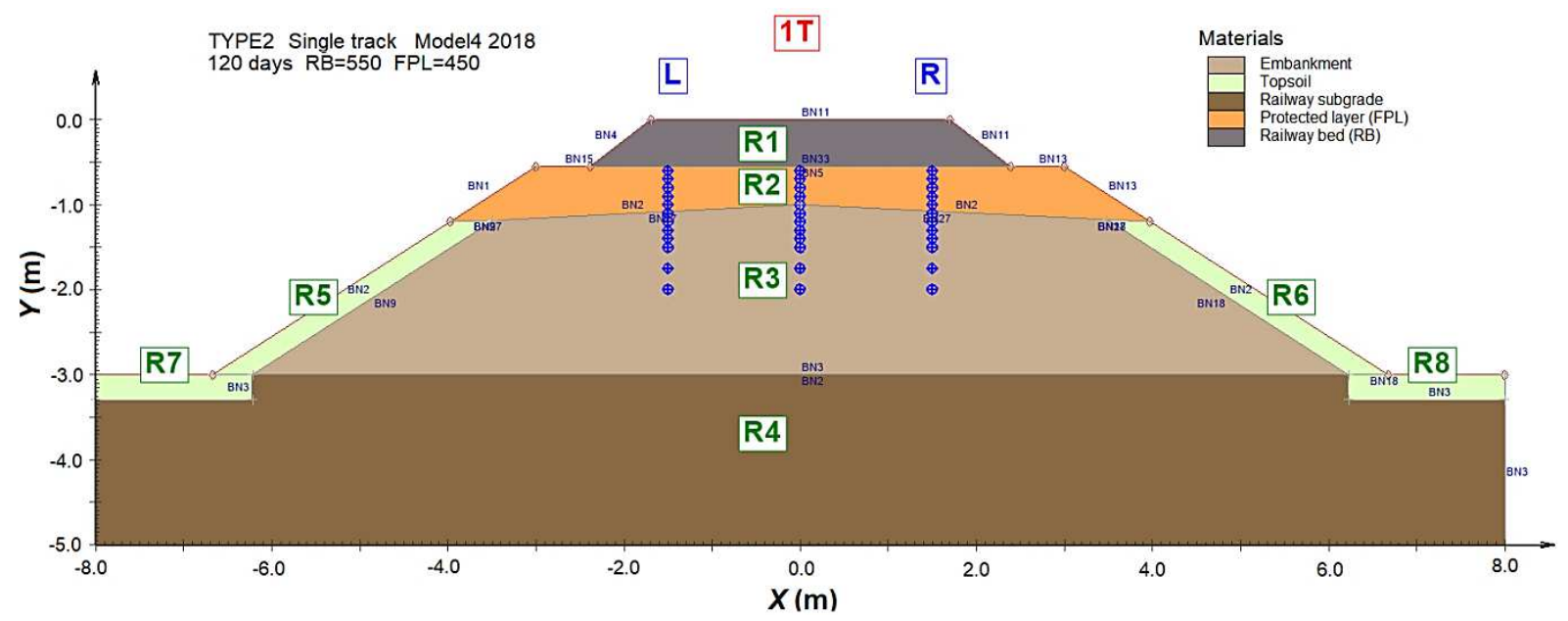

Fig. 3: Freezing of the subgrade layers $-h_{F P L}=0.45 \mathrm{~m} ; h_{\text {snow }}=0.00$ to $0.30 \mathrm{~m}$.

These considerations about snow cover height also apply for $h_{F P L}=0.60 \mathrm{~m}$. The course of values of the freezing is more favourable than $h_{F P L}=0.45 \mathrm{~m}$, Fig. 4 . The final evaluation of the experimental test is in Fig. 8b.

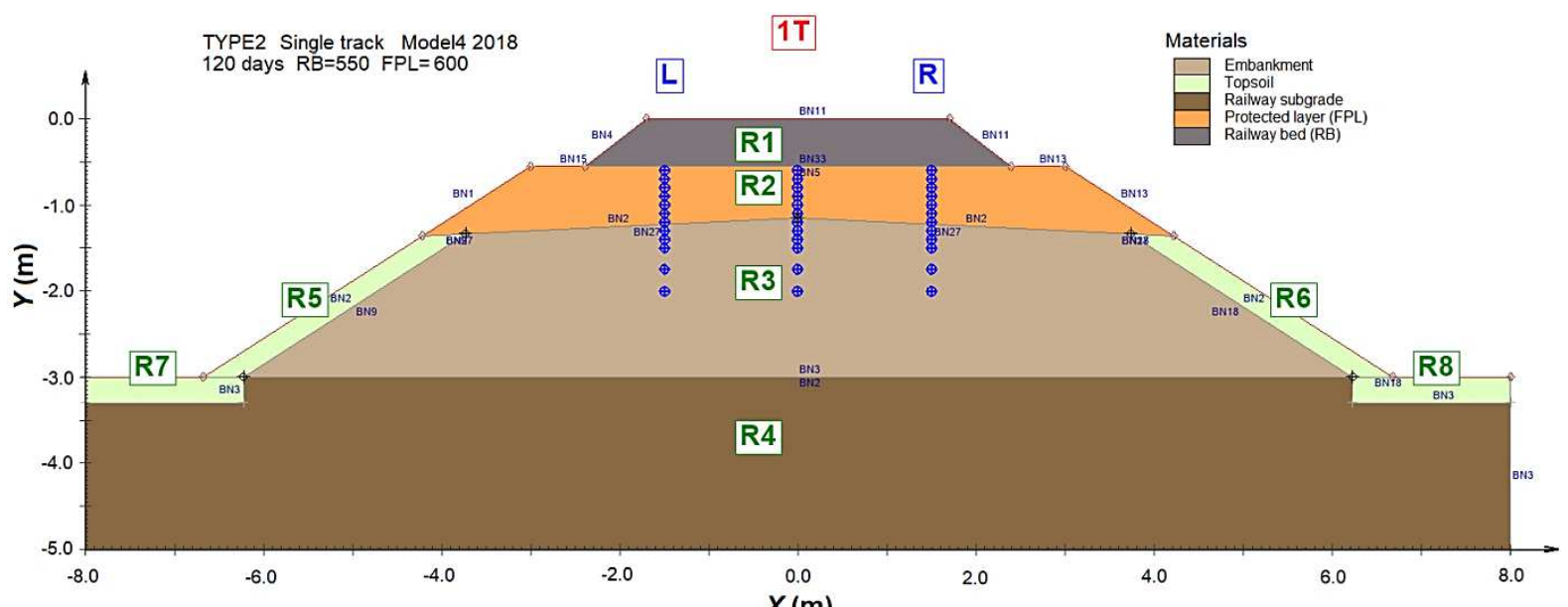

Fig. 4: Freezing of the subgrade layers $-h_{F P L}=0.60 \mathrm{~m} ; h_{\text {snow }}=0.00$ to $0.30 \mathrm{~m}$.

\section{Double-track - model experiment}

In the case of a double-track railway in Fig. 5, the volume of the built-in material can absorb more heat, or keep it from the previous summer and autumn periods during the winter. A double-track railway with the same height of the embankment will achieve better results in terms of anti-freezing resistance.

All conditions such as: material characteristics of the layers, climatic loads, etc. remain the same as in the previous experiment on the single-track with high embankment so that we can compare the "zero isotherm" $\left(0^{\circ} \mathrm{C}\right)$ in the figures Fig. 6 to Fig. 8. 
The results of the double track experiment with the embankment are shown with their values in Fig. $7\left(h_{F P L}=0.45 \mathrm{~m}\right)$, where are left: (a) for $h_{\text {snow }}=0.00 \mathrm{~m}$, (b) $h_{\text {snow }}=0.10 \mathrm{~m}$, (c) $h_{\text {snow }}=0.20 \mathrm{~m}$ and (d) $h_{\text {snow }}=0.30 \mathrm{~m}$. Similar values were also achieved with $h_{F P L}=0.60 \mathrm{~m}$ (right in Fig. 7), which also satisfy.

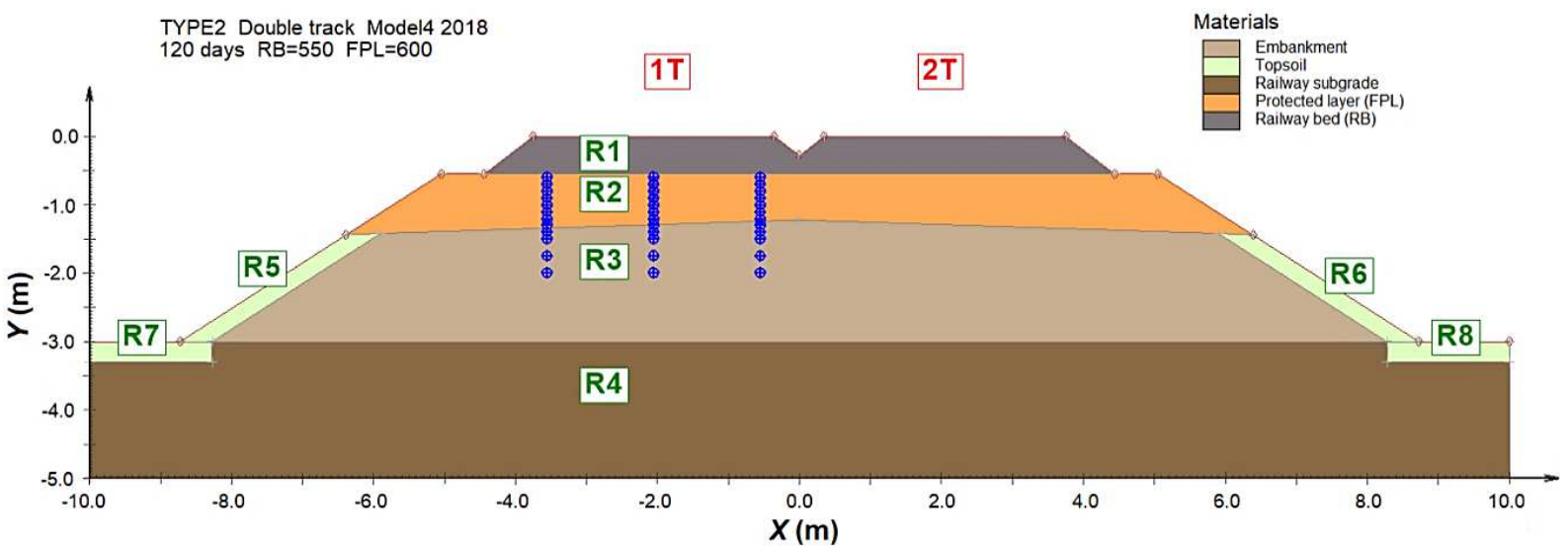

Fig. 5: Freezing of the subgrade layers $-h_{F P L}=0.60 \mathrm{~m} ; h_{\text {snow }}=0.00$ to $0.30 \mathrm{~m}$.

\section{Experiment evaluation}

During the whole numerical modelling experiment, the technical and thermal characteristics of the structural materials in the layers were the same (during the experiment, only the dimensional values of the cross sectional profiles for single-track and double-track with high embankment were changed). In the experiment we gradually changed a particular parameter by the same increase of climate change in the model, for example height of the snow layer $h_{\text {snow }}=0.00$ to $0.30 \mathrm{~m}$. In our case, the increase in frost resistance has improved. On the contrary, we experienced problems in winter without snow or a very low layer of $h_{\text {snow }}$, if it would freeze for 120 days according to the graph in the Fig. 2a.

The hypothesis was tested on two structural protective layers (FPL) at $h_{F P L}=0.45$ and $0.60 \mathrm{~m}$. With a larger bulk of material, we have shown that a higher dose of heat is bound (for example by comparing models of the low-embankment in the Department of Railway Engineering and Track Management (KŽSTH) with $h_{F P L}=0.45 \mathrm{~m}$, TYPE 2 or TYPE 1 for single-track), in research VEGA [1]. This applies to the winter periods of our geographical area (town of Žilina, Slovakia), where winter period usually ends after about 120 days, whereby we loaded the models with higher frost values $I_{f 120}=-600{ }^{\circ} \mathrm{C}$. We also used frost conditions at $I_{f 120}=-800{ }^{\circ} \mathrm{C}$ in the research, but they are not included in this paper.

For the experiment a numerical modelling, represented by SV-HEAT [1], created by experts and researchers in Canada, who paid higher attention to this project (Canada is generally cooler in winter than in Slovakia, in [12] in 2018, [13] in 2016, [14] in 2018 and [15] in 2013) was used.

The determined result values are shown in the figures Fig. 6 and Fig. 7, where the freezing values for the track axis are given. And at the rail tracks tags are added whether they meet " $<$ " or not ">" resistance to freezing; the marking is of course also distinguished by colour (in Fig. 8 - red is not satisfying). 


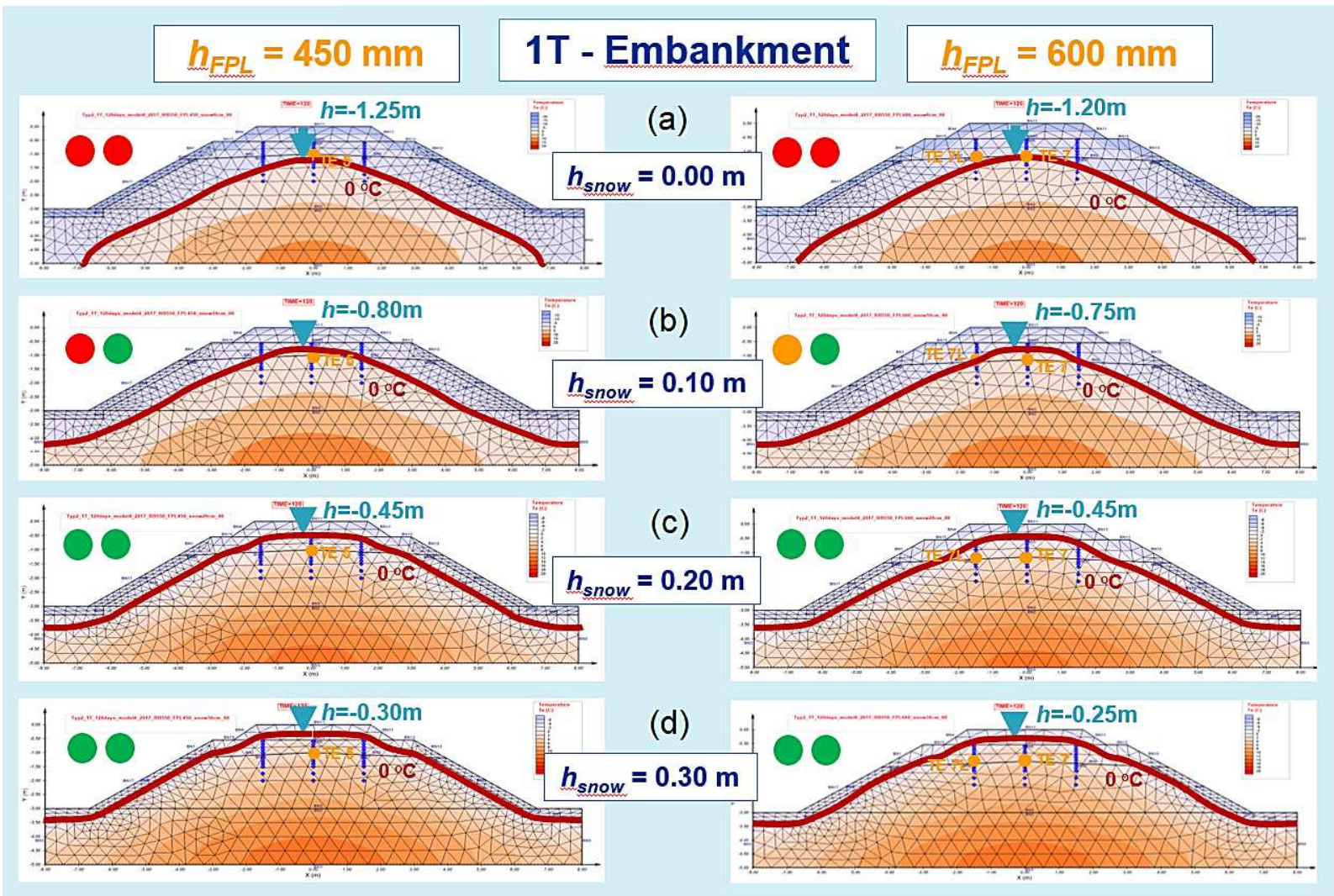

Fig. 6: Freezing depth during experiment - single track, high embankment.

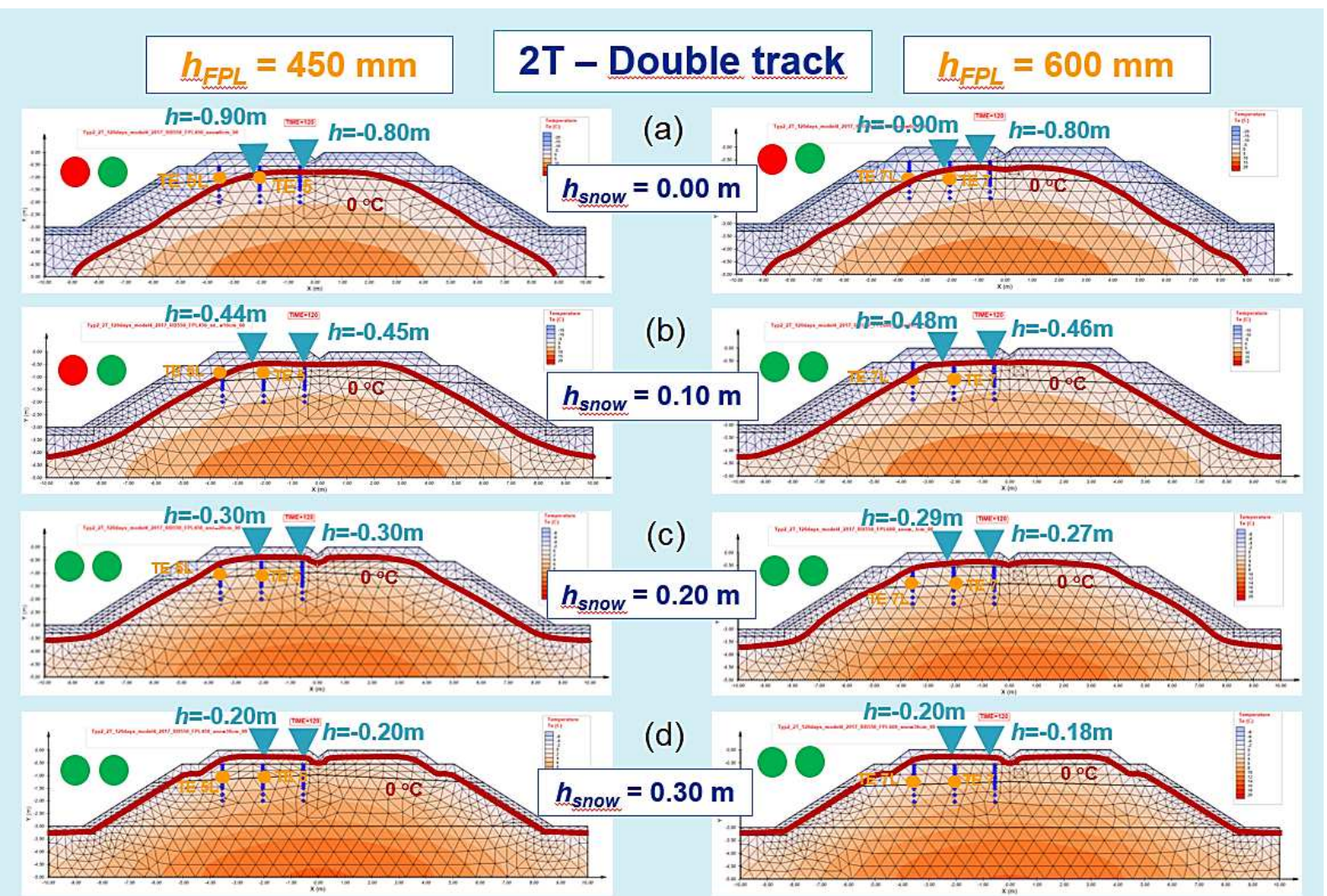

Fig. 7: Freezing depth during experiment - double-track railway, high embankment. 
Finally, we can describe a clear summary of the results both graphically, for example, for a double-track with high embankment for both thicknesses of $h_{F P L}$ in the Fig. 8 , where evaluation is marked by a ring (green - satisfies, orange - close to the limit, red - does not satisfy).

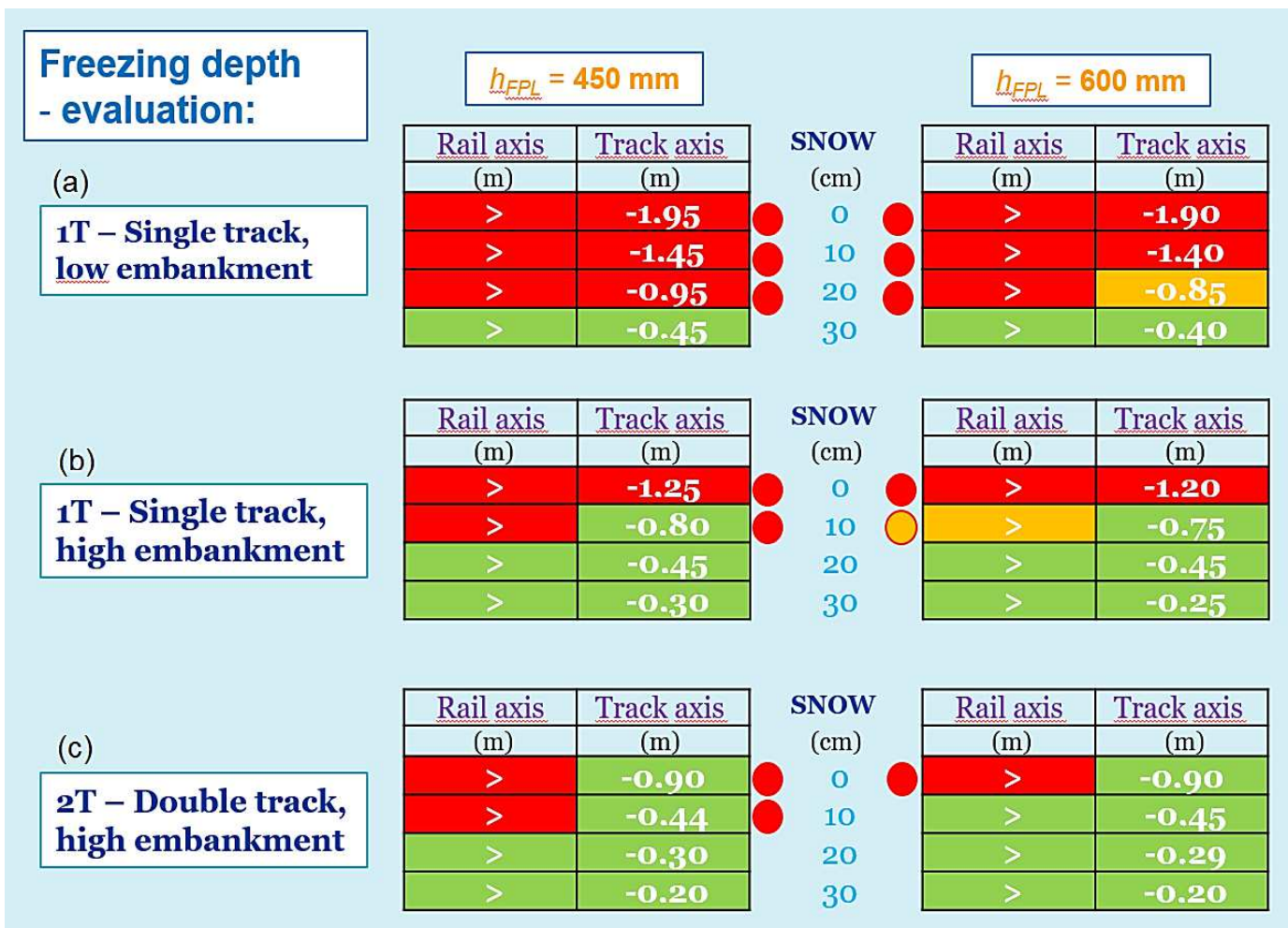

Fig. 8: Determination of freezing depth - final evaluation.

\section{Conclusions}

Numerical modelling methods are useful for verifying the temperature regime results, for example, we have been able to model different temperature climatic loads (designated as climate 1 to climate 5) at different thicknesses of the protective layer (in our experiment $h_{F P L}=0.45$ and $0.60 \mathrm{~m}$ ). A prerequisite for the correctness of the results is several elements of the model, which must be correctly kept and entered. Because of the relevance of the results obtained in the modelling of our experiment, it is very important to initially set all the temperature input values in the particular structural layers $R_{i}$ and the foundation below the railway formation to a certain depth (the so-called experiment time at 0:00 o'clock). The experiment starts from the given input values. It is necessary that the model corresponds precisely to the shape of the railway structure and dimensional reality, as well as the correct position and height of all temperature-controlled points in the railway subgrade structure.

An important factor is knowledge, i.e. the use of relevant values for the characteristics of the embedded materials in layers $R_{i}$ (for example coefficient of thermal conductivity, bulk material characteristics, etc.). These values have to be determined in laboratory, otherwise we have to use the characteristic standardized values from norms.

In the experiment, the load of the highest frost index over the last decades in Slovakia, that is from real winter in the region area of town of Poprad (conditions of the Northern Slovakia) were used. It has been shown by experiment that the size of the track formation influences the freezing of its subbalast layers. The greater the mass in the core of the railway formation is, the smaller are the depths of freezing, i.e. in the experiment we proceeded from the single-track with the low embankment, through the high embankment to the double-track on the high embankment.

\section{Acknowledgements}

The presented parts of the paper were created within the framework of the research activities VEGA 1/0275/16 [8] Optimization design of sleeper subgrade due to non-traffic load aspect, 2016 - 
2019 by the Department of Railway Engineering at the Faculty of Civil Engineering of University of Žilina (DRE-FCE-UNIZA).

\section{References}

[1] SV-HEAT: 2D/3D Finite element - freeze/thaw modelling. FlexPDE. SVOFFICE - Geotechnical modelling suite, SVOFFICE ${ }^{\mathrm{TM}_{5}}$ /GE and SV-HEAT ${ }^{\mathrm{TM}} \mathrm{GE}$. SoilVision systems Ltd., Saskatoon, Saskatchenwan, Canada, 2018, http://www.soilvision.com.

[2] HODÁS, S. - IŽVOLT, L.: Modelling of temperature regime of railway track structure and its comparison with the results of experimental measurements. COMPRAIL XIV Railway engineering design and optimization, Rome, Italy, 2014, pp. 253 - 265. WESSEX Institute of Technology, http://www.wessex.ac.uk, WitPress, Southampton, United Kingdom, http://www.witpress.com, doi: 10.2495/CR140201.

[3] WANG, S. - LV, Q. - BAAJ, H. - LI, X. - ZHAO, Y.: Volume change behaviour and microstructure of stabilized loess under cyclic freeze-thaw conditions. Canadian Journal of Civil Engineering, Vol. 43, Iss. 10, 2016, pp. 865 - 874, doi: 10.1139/cjce-2016-0052.

[4] BILODEAU, J. P. - DORÉ, G. - DROLET, F. P. - CHAUMONT, D.: Correction of air freezing index for pavement frost protection design to consider future climate changes. Canadian Journal of Civil Engineering, Vol. 43, Iss. 4, 2016, pp. 312 - 319, doi: 10.1139/cjce-2015-0475.

[5] ŠESTÁKOVÁ, J.: Quality of slab track construction - track alignment design and track geometry. Civil and Environmental Engineering, Vol. 11, Iss. 1, 2015, pp. 2 - 9, doi: 10.1515/cee-2015-0001.

[6] HODÁS, S. - IŽVOLT, L. - DOBEŚ, P.: Preliminary results and conclusions from mathematical modelling of thermal regime of railway track structure. International journal of computational methods and experimental measurements, Vol. 4, Iss. 2, 2016, pp. 69 - 79. WESSEX Institute of Technology, http://www.wessex.ac.uk, WitPress, Southampton, United Kingdom, http://www.witpress.com, doi: 10.2495/CMEM-V4-N2-69-79.

[7] IŽVOLT, L. - DOBEŠ, P. - PIEŠ, J.: Updating the design map of frost indexes as a prerequisite for relevant assessment of track substructure for non-traffic load. Civil and Environmental Engineering, Vol. 14, Iss. 2, 2018, pp. 116 - 123.

[8] VEGA 1/0275/16: Optimization design of sleeper subgrade due to non-traffic load aspect. Scientific research, Dep. of railway engineering, Faculty of civil engineering, University of Žilina, Žilina, http://svf.uniza.sk/kzsth, VEGA - Ministry of education, Science \& research of the Slovak Republic, Bratislava, SK, 2016-2019, http://www.minedu.sk/about-the-ministry/.

[9] ZVOLENSKÝ, P. - GRENČíK, J. - KAŠIAR, L'. - VOLNA, P. - LICCIARDELLO, R.: Modelling and experimental analysis of noise transmission through wall of a railway vehicle. Communications Scientific Letters of the University of Žilina, Vol. 19, Iss. 2A, 2017, pp. 60 - 67, http://www3.uniza.sk/komunikacie/archiv/2017/2a/2a_2017en.pdf.

[10] HODÁS, S. - PULTZNEROVÁ, A.: Modelling of railway track temperature regime with real heattechnical values for different climatic characteristics. Civil and Environmental Engineering, Vol. 13, Iss. 2, 2017, pp. 134 - 142, doi: 10.1515/cee-2017-0018.

[11] HODÁS, S.: Design of railway track for speed and high-speed Railways. $23^{\text {rd }}$ Russian-PolishSlovak Seminar on Theoretical Foundation of Civil Engineering. Procedia Engineering, Vol. 91, 2014, pp. 256 - 261. Wroclaw, Poland, doi: 10.1016/j.proeng2014.12.056.

[12] FORD, J. D. - COUTURE, N. - BELL, T. - CLARK, D. G.: Climate change and Canada's north coast: research trends, progress, and future directions. Environmental Reviews, Vol. 26, Iss. 1, 2018, pp. 82 - 92, doi: 10.1139/er-2017-0027.

[13] ASEFZADEH, A. - HASHEMIAN, L. - HAGHI, N. T. - BAYAT, A.: Evaluation of spring load restrictions and winter weight premium duration prediction methods in cold regions according to field data. Canadian Journal of Civil Engineering, Vol. 43, Iss. 7, 2016, pp. 667 - 674, doi: 10.1139/cjce-2015-0554.

[14] IŽVOLT, L. - DOBEŠ, P. - HODÁS, S.: Impact of the method of rail track routing on the thermal regime of subgrade structure - numerical modelling of non-trafic load. International Journal of Transport Development and Integration, Vol. 2, Iss. 3, 2018, pp. 250 - 257. WitPress, Southampton, United Kingdom, http://www.witpress.com, doi: 10.2495/TDI-V2-N3-250-257.

[15] IŽVOLT, L. - DOBEŠ, P. - MEČÁR, M.: Contribution to the methodology of the determination of the thermal conductivity coefficients $\lambda$ of materials applied in the railway subbase structure. Communications - Scientific Letters of the University of Žilina, Vol. 13, Iss. 4, 2013, pp. 9 - 17, http://www3.uniza.sk/komunikacie/archiv/2013/4/4_2013en.pdf. 